\title{
Transition Rate from EGFR-TKI to Cytotoxic Chemotherapy Patients with EGFR Mutation-positive Lung Adenocarcinoma
}

\author{
YOHEI KAWAGUCHI, TETSUYA OKANO, MASATOSHI KAKIHANA, \\ NAOHIRO KAJIWARA, TATSUO OHIRA and NORIHIKO IKEDA
}

Department of General Thoracic Surgery, Tokyo Medical University, Tokyo, Japan

\begin{abstract}
Background/Aim: The transition rate from firstline epidermal growth factor receptor tyrosine kinase inhibitors (EGFR-TKIs) to cytotoxic chemotherapy $(\mathrm{Ct})$ is poor. The prognosis according to treatment sequence and the reasons patients could not shift from first-line EGFR-TKIs to Ct were herein analyzed. Patients and Methods: Overall, 159 epidermal growth factor receptor mutation-positive adenocarcinoma patients were enrolled in this study. Results: The median survival times of EGFR-TKIs combined with Ct and EGFR-TKIs were 59.8 months and 22.5 months, respectively $(p<0.001)$ and of patients who received EGFRTKIs first and Ct first were 38.8 months and 66.4 months, respectively $(p=0.016)$. The main reasons patients could not make the transition to Ct was worsening of performance status and patient's preference. Conclusion: EGFR-TKIs and Ct lead to a good prognosis in EGFR mutation-positive adenocarcinoma patients. It is necessary to consider the timing when changing the treatment strategy before treatment options are limited.
\end{abstract}

Epidermal growth factor receptor (EGFR) mutations, most of which have been detected in lung adenocarcinoma, are a predictor of response to EGFR tyrosine kinase inhibitors (EGFR-TKIs) (1-3). Previously, platinum-based cytotoxic chemotherapy $(\mathrm{Ct})$ was the standard treatment for advanced or recurrent non-small cell lung cancer (NSCLC) until the advent of EGFR-TKIs (4-5). After approval of EGFR-TKIs by the United States Food and Drug Administration, the treatment strategy for EGFR mutation-positive NSCLC was dramatically changed. EGFR-TKIs have improved the prognosis of EGFR mutation-positive NSCLC patients relative to that of $\mathrm{Ct}(6-8)$.

Correspondence to: Tetsuya Okano, Tokyo Medical University Department of General Thoracic Surgery; 6 Chome-7-1 Nishishinjuku, Shinjuku, Tokyo, 160-0023, Japan. Tel: +819040085067, e-mail: tokano@tokyo-med.ac.jp

Key Words: Transition rate, lung adenocarcinoma, gene mutation, EGFF-TKI.
Furthermore, EGFR-TKIs are well tolerated by patients because they are orally ingested and have low gastrointestinal toxicity or bone marrow suppression.

For these reasons, EGFR-TKIs have become the first-line treatment for EGFR-positive NSCLC patients worldwide according to the National Comprehensive Cancer Network $(\mathrm{NCCN})$. However, the role of $\mathrm{Ct}$ in EGFR mutation-positive patients is important. Several studies have reported the importance of using both EGFR-TKIs and $\mathrm{Ct}$ in EGFR mutation-positive NSCLC patients. Inoue reported EGFR mutation-positive patients who received both EGFR-TKIs and $\mathrm{Ct}$ had a better prognosis than patients who received EGFRTKIs alone (9). Although $\mathrm{Ct}$ still has an important role in the treatment sequence of EGFR mutation-positive NSCLC patients, the transition rate to $\mathrm{Ct}$ after failure of primary EGFR-TKIs treatment has been poor. Furthermore, there exist few studies that compared the effect of the order of administration of EGFR-TKIs or Ct on overall survival (OS).

To the best of our knowledge, no studies have investigated why many patients cannot make the transition from EGFRTKIs treatment to $\mathrm{Ct}$. The purpose of this study was to evaluate the differences in OS for various treatment sequences that include EGFR-TKIs, the transition rate from EGFR-TKIs to $\mathrm{Ct}$, and to determine why patients cannot make the transition to $\mathrm{Ct}$.

\section{Patients and Methods}

Study design. This was a retrospective single-institution study examining patients with EGFR mutation-positive adenocarcinoma. Patient selection. A total of 229 consecutive clinical stage IIIB, IV (according to the 7th Edition of the TNM Classification for Lung and Pleural Tumors of the Union for International Cancer Control) (10) patients with $E G F R$ mutation-positive adenocarcinoma treated with EGFR-TKIs and who showed postoperative recurrent adenocarcinoma between January 2010 and December 2016 at Tokyo Medical University Hospital were enrolled. A total of 45 patients who had undergone first-line treatment and 7 patients who received chemoradiotherapy as a first-line treatment were excluded. We also excluded 18 patients who received osimertinib that was efficacious and were shown to have developed the tolerance gene exon19 T790M during treatment with EGFR-TKIs to avoid heterogeneous prognosis 
of the EGFR-TKIs alone group (11). Therefore, there is a risk that the prognosis of patients who received EGFR-TKIs alone will be heterogeneous. Finally, 159 eligible patients were included in our study. Patients were categorized into 2 groups: patients who received EGFR-TKIs combined with Ct and those who received EGFR-TKIs only. The patients who received EGFR-TKIs combined with $\mathrm{Ct}$ were separated into 2 subgroups: those who received EGFR-TKIs first and those who received $\mathrm{Ct}$ first (Figure 1). We reviewed the medical records of the patients regarding their treatment sequence and transition rate from first-line EGFR-TKIs to $\mathrm{Ct}$.

EGFR mutation analysis. All of the specimens collected were fixed in $10 \%$ formalin and embedded in paraffin. Representative sections were routinely stained with hematoxylin and eosin and were reviewed by experienced pathologists to confirm that the sections included carcinoma cells. EGFR mutation analysis of histologic specimens was screened using the cycleave polymerase chain reaction (PCR) method.

Statistical analysis. OS and TKI-PFS were estimated by using the Kaplan-Meier method, and differences in survival rates were determined by using the log-rank test. OS was defined as the time elapsed from the date of administration of first-line treatment to the date of death and defined progression-free survival for the EGFRTKIs (TKI-PFS) group who received EGFR-TKIs first as the time from the date of administration of EGFR-TKIs first to the date of stopping administration of EGFR-TKIs or death.

Hazard ratios and their 95\% confidence intervals (CIs) were performed using the Cox proportional hazards model to determine independent predictors of the OS. All significant variables $(p<0.05)$ in the univariate analyses were entered into the multivariate analyses using a stepwise variable selection procedure to adjust for potential confounding factors. $p$-Values of $<0.05$ were considered as indicative of statistical significance. Statistical analyses were performed by using the SPSS statistical software package (version 24.0; SPSS, Inc, Chicago, IL, USA).

\section{Results}

Patients. The patients' characteristics are summarized in Table I. The median follow-up period was 22.5 months. Of the total 159 patients, $113(71 \%)$ were female, 114 (72\%) were $<75$ years old, and 86 (54\%) showed postoperative recurrence. The most frequent subtypes of EGFR were exon 19 deletion in 84 patients $(53 \%)$ followed by exon 21 L858R in 54 patients (34\%). EGFR-TKIs were administered as a first-line therapy in $93(58 \%)$ patients, and $\mathrm{Ct}$ was administered in $66(42 \%)$ patients (Figure 2). The most common EGFR-TKI administered as a first-line was gefitinib in $133(84 \%)$ of 159 patients. The most frequent type of recurrence at the time of failure of the first-line treatment was primary tumor or pulmonary metastasis (62 of 159 patients). Brain or central nervous system (CNS) metastasis was observed in 32 patients, and bone metastasis was observed in 20 patients.

Transition rate. Among the 93 patients who were administered EGFR-TKIs as a first-line treatment, 32 (34\%) patients transitioned to $\mathrm{Ct}$. The reasons for why the
Table I. Patient characteristics $(n=159)$.

\begin{tabular}{|c|c|}
\hline Variable & Number $(\%)$ \\
\hline \multicolumn{2}{|l|}{ Gender } \\
\hline Male & $46(29)$ \\
\hline Female & $113(71)$ \\
\hline \multicolumn{2}{|l|}{ Age; median (range) (years) } \\
\hline$<75$ & $114(72)$ \\
\hline$\geq 75$ & $45(28)$ \\
\hline \multicolumn{2}{|l|}{ Clinical stage } \\
\hline III/IV & $73(46)$ \\
\hline Recurrence & $86(54)$ \\
\hline \multicolumn{2}{|l|}{ Performance status } \\
\hline $0-1$ & $114(72)$ \\
\hline$\geq 2$ & $20(13)$ \\
\hline Unknown & $25(15)$ \\
\hline \multicolumn{2}{|l|}{ EGFR mutation status } \\
\hline 19del & $83(52)$ \\
\hline L858R & $55(34)$ \\
\hline T790M+19del & $1(1)$ \\
\hline $\mathrm{T} 790 \mathrm{M}+\mathrm{L} 858 \mathrm{R}$ & $3(3)$ \\
\hline Others & $10(6)$ \\
\hline Unknown & $7(4)$ \\
\hline \multicolumn{2}{|l|}{ First-line treatment } \\
\hline EGFR-TKIs & $93(58)$ \\
\hline Gefitinib & $78(49)$ \\
\hline Elrotinib & $9(6)$ \\
\hline Afatinib & $2(1)$ \\
\hline Elrotinib+Bevasizumab & $4(2)$ \\
\hline $\mathrm{Ct}$ & $66(42)$ \\
\hline \multicolumn{2}{|l|}{ Treatment sequence } \\
\hline EGFR-TKIs $\rightarrow \mathrm{Ct}$ & $32(20)$ \\
\hline $\mathrm{Ct} \rightarrow$ EGFR-TKIs & $66(42)$ \\
\hline EGFR-TKIs only & $61(38)$ \\
\hline \multicolumn{2}{|l|}{ Initial recurrence cite at first-line PD } \\
\hline CNS & $31(19)$ \\
\hline Bone & $20(13)$ \\
\hline Hilum or mediastinal lymph node & $16(9)$ \\
\hline Liver & $8(5)$ \\
\hline Effusion & $10(6)$ \\
\hline Primary lesion or pulmonary metastasis & $64(40)$ \\
\hline Others & $32(20)$ \\
\hline
\end{tabular}

EGFR-TKIs: Epidermal growth factor receptor tyrosine kinase inhibitors; PD: progression disease; CNS: central nerve system; Ct: cytotoxic chemotherapy.

remaining 61 patients received EGFR-TKIs only, are presented in Table II. The most common reason patients could not shift to $\mathrm{Ct}$ was worsening performance status (PS), and the second most common reason was the patient's preference. Six patients were unable to continue treatment because they showed grade 3 or 4 EGFR-TKI-induced adverse events, such as interstitial lung disease.

Overall survival and progression-free survival. The median OS times for EGFR-TKIs combined with Ct and for EGFRTKIs only were 59.8 months $(95 \% \mathrm{CI}=50.2-69.5)$ and 22.5 


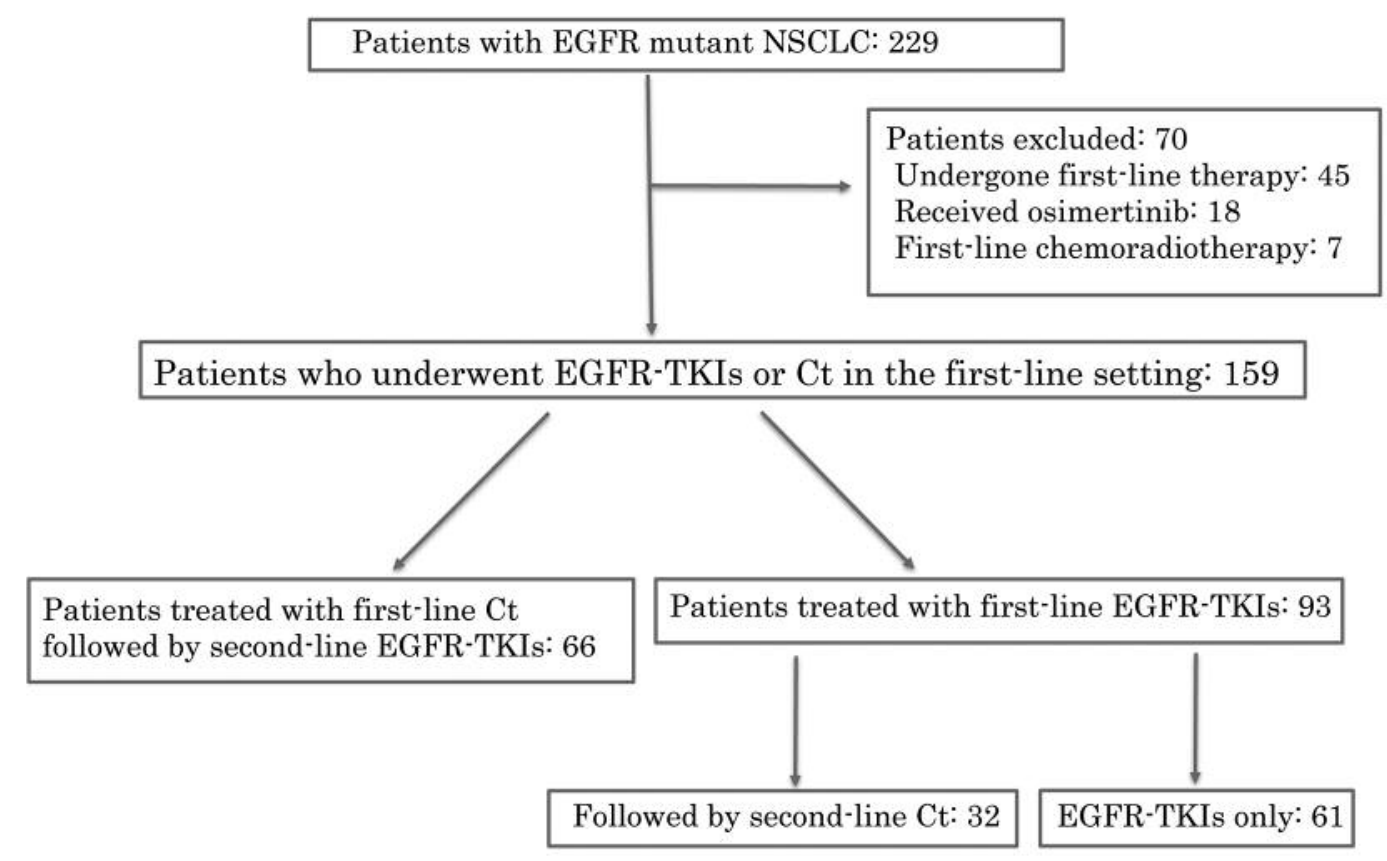

Figure 1. Flow chart showing the progress of the study. NSCLC: Non-small cell lung cancer; EGFR-TKI: epidermal growth factor tyrosine kinase inhibitor; Ct: cytotoxic chemotherapy.

months $(95 \% \mathrm{CI}=17.8-27.1)$, respectively. There was a statistically significant difference in OS between EGFR-TKIs combined with CT and EGFR-TKIs only $(p<0.001)$ (Figure $2 \mathrm{~A})$. The median survival time of the patients who received EGFR-TKIs first and who received $\mathrm{Ct}$ first were 38.8 months $(95 \% \mathrm{CI}=33.7-43.9)$ and 66.4 months $(95 \% \mathrm{CI}=55.5-77.3)$, respectively (Figure $2 \mathrm{~B}$ ). There was a statistically significant difference in OS times between the groups who received EGFR-TKIs first or Ct first $(p=0.016)$. The TKI-PFS for each treatment sequence are shown in Figures 2C and 2D. The median TKI-PFS times of the patients who received EGFF-TKIs combined with $\mathrm{Ct}$ and of the patients who received EGFR-TKIs only were 12.0 months $(95 \% \mathrm{CI}=8.7$ 15.3), and 10.7 months (95\% CI=7.5-13.9), respectively. There was no significant difference in the TKI-PFS times between the patients who received EGFR-TKIs with combined $\mathrm{Ct}$ and those who received EFFR-TKIs without combined $\mathrm{Ct}(p=0.256)$. The median TKI-PFS times of the patients who received EGFR-TKI first and $\mathrm{Ct}$ first were 14.3 months $(95 \% \mathrm{CI}=11.4-17.2)$, and 11.3 months $(95 \% \mathrm{CI}=9.03$ 13.6), respectively. There was no significant difference in the TKI-PFS times between the patients who received EGFRTKI first or Ct first ( $p=0.560)$. The results of the multivariate analysis for OS are presented in Table III. Postoperative recurrence and treatment sequence were independent prognostic factors.
Table II. Reasons why patients could not shift to cytotoxic chemotherapy.

\begin{tabular}{lrrr}
\hline Variable & All & $<75$ & $\geq 75$ \\
\hline Worsening PS & 33 & 16 & 17 \\
Patient's preference & 17 & 10 & 7 \\
Adverse event & 6 & 2 & 4 \\
Unknown & 7 & 5 & 2 \\
\hline
\end{tabular}

PS: Performance status.

\section{Discussion}

A total of 159 EGFR mutation-positive adenocarcinoma patients treated with EGFR-TKIs were retrospectively examined. In our study, patients who received EGFR-TKIs combined with $\mathrm{Ct}$ had significantly longer OS than patients who received EGFR-TKIs only. The present study OS results are consistent with those of these previous studies in patients treated with EGFR-TKIs. The transition rate to $\mathrm{Ct}$ after EGFR-TKIs was poor. Kato reported that of the patients who could not receive both EGFR-TKIs and $\mathrm{Ct}$ early, most of them had received EGFR-TKI first (12). The researchers pointed out the risk of missing the timing of administration of subsequent therapy. In the present study, only $34 \%$ of patients who received EGFR-TKIs as first-line treatment 
A

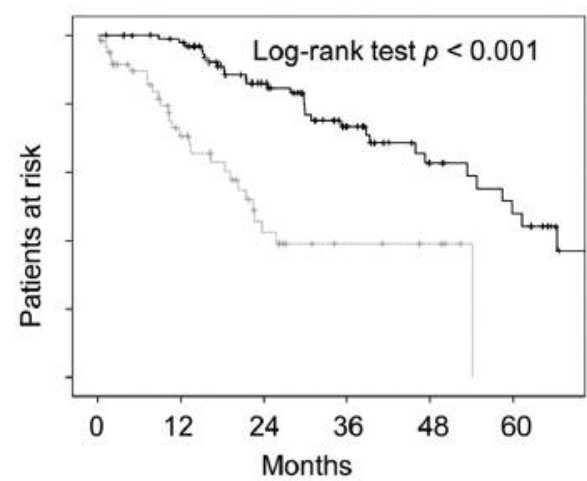

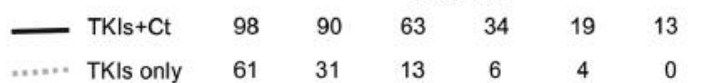

C TKI-PFS according to combined $\mathrm{Ct}$

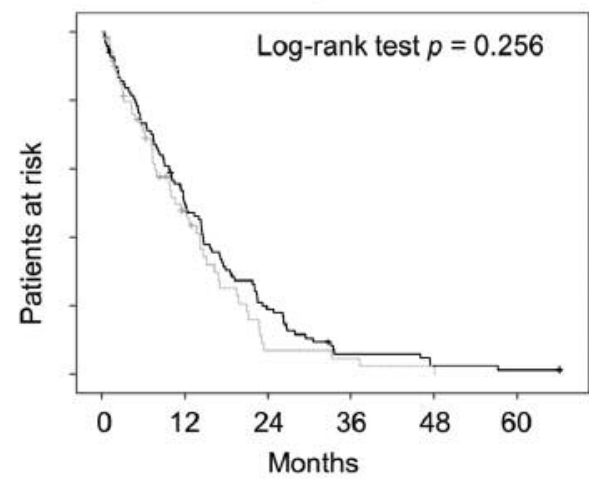

B
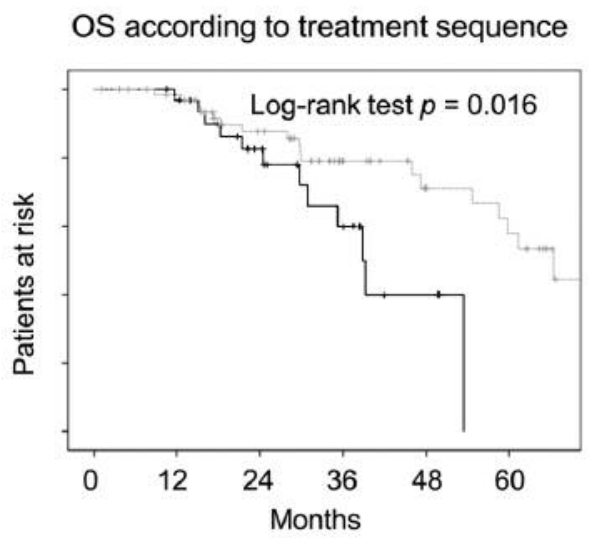

TKI first

$\begin{array}{cccccc}32 & 30 & 19 & 9 & 3 & 0 \\ 66 & 60 & 44 & 25 & 16 & 13\end{array}$

D TKI-PFS according to treatment sequence

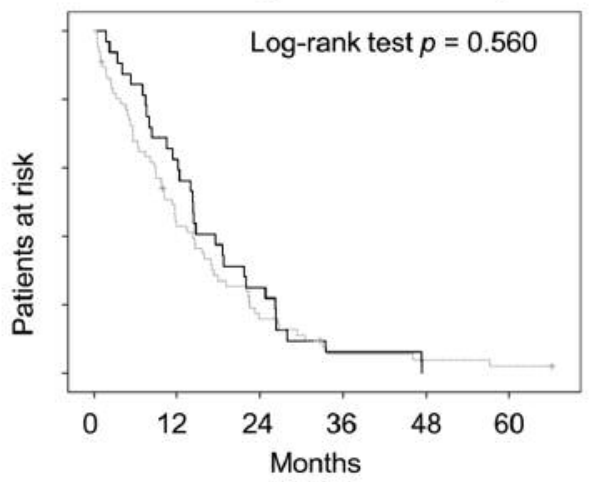

TKI first

$\begin{array}{llrrrr}32 & 20 & 8 & 2 & 0 & 0\end{array}$

Figure 2. Kaplan-Meier curves for overall survival (OS) and TKI-progression free survival (TKI-PFS).

Table III. Multivariate analysis of overall survival.

\begin{tabular}{|c|c|c|c|c|}
\hline \multirow[b]{2}{*}{ Variable } & \multirow{2}{*}{$\begin{array}{c}\text { Univariate analysis } \\
p \text {-Value }\end{array}$} & \multicolumn{3}{|c|}{ Multivariate analysis (MVA) } \\
\hline & & ORR & $95 \% \mathrm{CI}$ & $p$-Value \\
\hline \multicolumn{5}{|l|}{ Gender } \\
\hline Female (vs. male) & 0.786 & & Not included in MVA & \\
\hline \multicolumn{5}{|l|}{ Age (years) } \\
\hline$\geq 75(v s .<75)$ & 0.203 & & Not included in MVA & \\
\hline \multicolumn{5}{|l|}{ Clinical stage } \\
\hline Recurrence (vs III/IV) & 0.002 & 0.374 & $0.220-0.636$ & $<0.001$ \\
\hline \multicolumn{5}{|l|}{ EGFR mutation status } \\
\hline 21L858R (vs. 19del) & 0.841 & & Not included in MVA & \\
\hline Others (vs. 19del) & 0.148 & & Not included in MVA & \\
\hline \multicolumn{5}{|l|}{ Treatment sequence } \\
\hline \multicolumn{5}{|l|}{ TKI only } \\
\hline TKI first ( vs. TKI only) & 0.023 & 0.410 & $0.206-0.817$ & 0.011 \\
\hline Ct first (vs. TKI only) & $<0.001$ & 0.159 & $0.079-0.320$ & $<0.001$ \\
\hline
\end{tabular}

EGFR: Epidermal growth factor receptor; Ct: cytotoxic chemotherapy; TKI: tyrosine kinase inhibitor. 
could shift to subsequent $\mathrm{Ct}$. The main reason why patients could not shift to $\mathrm{Ct}$ was worsening of PS. A higher incidence of brain metastasis or carcinomatous meningitis can lead to worsening of PS. In NSCLC patients who are EGFR mutation positive, brain metastasis or carcinomatous meningitis could not be controlled with the EGFR-TKI therapy only and cause deterioration in quality of life (13).

Periodic checking and early detection of CNS metastasis are thought to help maintain good PS and a smooth transition to the next treatment. Another reason why patients could not shift to $\mathrm{Ct}$ was the patient's preference. According to our medical records, many patients wanted to continue the EGFR-TKI currently used or change to a different kind of EGFR-TKI because of the convenience of oral administration or anxiety about $\mathrm{Ct}$ after radiologic progressive disease (PD). Additionally, the quality of life scores significantly favored EGFR-TKI therapy (14).

According to the IMPRESS study, a randomized study that investigated the optimal treatment strategies for patients with NSCLC and acquired resistance to first-line EGFR TKIs, patients using continuous EGFR-TKIs after PD showed poor OS compared with that of patients who had shifted to $\mathrm{Ct}$ earlier (15). It is important for the attending doctor to convince patients to shift to the next treatment by providing sufficient informed consent.

Furthermore, the treatment sequence may also influence the OS. Patients who received Ct first showed better OS than patients who received EGFR-TKI first. Lifen et al. analyzed 9 clinical trials and reported that first-line EGFR-TKIs followed by second-line $\mathrm{Ct}$ was not superior to first-line $\mathrm{Ct}$ followed by second-line EGFR-TKIs (16).

In contrast to our study, NCCN and other guidelines recommend the use of EGFR-TKIs as first-line treatment for advanced or recurrent EGFR mutation-positive NSCLC patients $(17,18)$. The major reason to use EGFR-TKIs as firstline treatment is to avoid the risk of EGFR-TKIs being unusable for various reasons, such as interstitial lung disease. It is possible that patients treated with $\mathrm{Ct}$ first showed a better prognosis relative to patients who received EGFR-TKIs first because the $\mathrm{Ct}$ first group may have had better PS than the EGFR-TKI first group. Several studies have reported that good PS at the time of first-line treatment affects OS (19). The present study was based on medical records of the Tokyo Medical University Hospital, but there were many cases in which the PS was not stated clearly. In our hospital, platinumdoublet chemotherapy was only administered to patients with favorable PS, but EGFR-TKIs was also used for patients with poor PS at the start of treatment.

This study had several limitations that should be considered. First, the number of patients was so small that it may have affected the conclusions drawn from the statistical analysis. Second, this was a single-institution retrospective study. A large-scale prospective study with more cases would be useful in the future. Third, this study analyzed only patients treated with EGFR-TKIs and did not include patients not using EGFR-TKIs. It is unknown how many patients were not able to receive EGFR-TKIs during our observation period, but we can infer that their OS was poor. Finally, our present study is limited to cases in which T790M is not expressed or unknown for reasons such as not being able to re-biopsy after receiving EGFR-TKIs to avoid heterogeneous prognosis of the EGFR-TKIs alone group. Long-term observation is necessary to evaluate the OS of patients who are treated only with EGFR-TKIs, including osimertinib.

In conclusion, EGFR-TKIs combined with $\mathrm{Ct}$ for $E G F R$ mutation-positive adenocarcinoma patients showed longer OS than patients treated with EGFR-TKIs only. Treatment sequence is also involved in OS. Patients who received $\mathrm{Ct}$ prior to EGFR-TKIs showed favorable OS compared to patients who received EGFR-TKIs prior to CT. Attending doctors should assess the need for treatment change and persuade patients to transition to the next treatment at an appropriate time for best results.

\section{Acknowledgements}

This research was supported by AMED under Grant Number JP17ck0106295.

\section{References}

1 Mitsudomi T, Kosaka T and Yatabe Y: Biological and clinical implications of EGFR mutations in lung cancer. Int J Clin Oncol 11: 190-198, 2006.

2 Lynch TJ, Bell DW, Sordella R, Gurubhagavatula S, Okimoto RA and Brannigan BW: Activating mutations in the epidermal growth factor receptor underlying responsiveness of non-small-cell lung cancer to gefitinib. N Engl J Med 350: 2129-2139, 2004.

3 Paez JG, Janne PA, Lee JC, Tracy S, Greulich H and Gabriel S; EGFR mutations in lung cancer: correlation with clinical response to gefitinib therapy. Science 304: 1497-1500, 2004.

4 Hotta K, Matsuo K, Ueoka H, Kiura K, Tabata M and Tanimoto M: Meta-analysis of randomized clinical trials comparing cisplatin to carboplatin in patients with advanced non-small-cell lung cancer. J Clin Oncol 22: 3852-3859, 2004.

5 Hotta $\mathrm{K}$ and Matsuo K: Long-standing debate on cisplatin versus carboplatin-based chemotherapy in the treatment of advanced non-small cell lung cancer. J Thorac Oncol 2: 96, 2007.

6 Mok TS, Wu YL, Thongprasert S, Yang CH, Chu DT, Saijo N, Sunpaweravong P, Han B, Margono B, Ichinose Y, Nishiwaki Y, Ohe Y, Yang J, Chewaskulyong B, Jiang H, Duffield EL, Watkins CL, Armour AA and Fukuoka M: Gefitinib or carboplatin-paclitaxel in pulmonary adenocarcinoma. N Engl J Med 361: 947-957, 2009.

7 Maemondo M, Inoue A, Kobayashi K, Sugawara S, Oizumi S, Isobe H, Gemma A, Harada M, Yoshizawa H, Kinoshita I, Fujita Y, Okinaga S, Hirano H, Yoshimori K, Harada T, Ogura T, Ando M, Miyazawa H, Tanaka T, Saijo Y, Hagiwara K, Morita S, and Nukiwa T: Gefitinib or chemotherapy for non-small-cell lung cancer with mutated EGFR. N Engl J Med 362: 2380-2388, 2010. 
8 Rosell R, Carcereny E, Gervais R, Vergnenegre A, Massuti B Felip E, Palmero R, Gomez RG, Pallares C, Sanchez JM, Prota R, Cobo M, Garrido P, Longo F, Moran T, Insa A, Marinis FD, Corre R and Ares LP: Erlotinib versus standard chemotherapy as first-line treatment for European patients with advanced EGFR mutation-positive non-small-cell lung cancer (EURTAC): a multicentre, open-label, randomised phase 3 trial. Lancet Oncol 13: 239-246, 2012.

9 Inoue A, Kobayashi K, Maemondo M, Sugawara S, Oizumi S, Isobe H, Gemma A, Harada M, Yoshizawa H, Kinoshita I, Fujita Y, Okinaga S, Hirano H, Yoshimori K, Harada T, Saijo Y, Hagiwara K, Morita S and Nukiwa T: Updated overall survival results from a randomized phase III trial comparing gefitinib with carboplatin-paclitaxel for chemo-naive non-small cell lung cancer with sensitive egfr gene mutations (nej002). Ann Oncol 24: 54-59, 2013.

10 Sobin LH, Gospodarowicz MK and Wittekind C: International Union against Cancer. TNM Classification of Malignant Tumours. 7th ed. Chichester, West Sussex, UK. Hoboken, NJ, Wiley-Blackwell, 2010.

11 Mok TS, Wu YL, Ahn MJ, Garassino MC, Kim HR, Ramalingam SS, Shepherd FA, He Y, Akamatsu H, Theelen WSME, Lee CK, Sebastian M, Templeton A, Mann H, Marotti M, Ghiorghiu S and Papadimitrakopoulou VA: Osimertinib or Platinum-Pemetrexed in EGFR T790M-Positive Lung Cancer. N Engl J Med 376: 629-640, 2017.

12 Kato Y, Hotta K, Takigawa N, Nogami N, Kozuki T, Sato A,Ichihara E, Kudo K, Oze I, Tabata M, Shinkai T, Tanimoto M and Kura K: Factor associated with failure to administer subsequent treatment after progression in the first-line chemotherapy in EGFR-mutant non-small cell lung cancer: Okayama Lung Cancer Study Group experience. Cancer Chemother Pharmacol 73: 943-950, 2014.

13 Gui Q, Liu J, Li D and Xu C: Prolonged survival of patients with EGFR-mutated non-small cell lung cancer with solitary brain metastases treated with surgical resection of brain and lung lesions followed by EGFR TKIs. World J Surg Oncol 15: 184188,2017

14 Oizumi S, Kobayashi K, Inoue A, Maemondo M, Sugawara S, Yoshizawa H, Isobe H, Harada M, Kinoshita I, Okinaga S, Kato T, Harada T, Gemma A, Saijo Y, Yokomizo Y, Morita S, Hagiwara $\mathrm{K}$ and Nukiwa T: Quality of life with gefitinib in patients with EGFR-mutated non-small cell lung cancer: quality of life analysis of North East Japan Study Group 002 Trial. Oncologist 17: 863-870, 2012.
15 Mok TS, Kim SW, Wu YL, Nakagawa K, Y JJ, Ahn MJ, Wang J, Yang JC, Lou Y, Atagi S, Ponce S, Shi X, Rukazenkov Y, Haddad V, Thress KS and Soria JC: gefitinib plus chemotherapy versus chemotherapy in epidermal growth factor receptor mutation-positive non-small-cell lung cancer resistant to firstline gefitinib (IMPRESS): Overall Survival and Biomarker Analyses. J Clin Oncol 35: 4027-4034, 2017.

16 Qiao L, Wang J, Long G and Jiang Y: Sequential treatment of tyrosine kinase inhibitor and platinum-based doublet chemotherapy on EGFR mutant non-small cell lung cancer: a meta-analysis of randomized controlled clinical trials. Onco Targets Ther 10: 1279, 2017.

17 Ettinger DS, Wood DE, Akerley W, Bazhenova LA, Borghaei H, Camidge DR, Cheney RT, Chirieac LR, D'Amico TA, Demmy TL, Dilling TJ, Dobelbower MC, Govindan R1, Grannis FW Jr., Horn L, Jahan TM, Komaki R, Krug LM, Lackner RP, Lanuti M, Lilenbaum R, Lin J, Loo BW Jr., Martins R, Otterson GA, Patel JD, Pisters KM1, Reckamp K, Riely GJ, Rohren E, Schild SE, Shapiro TA, Swanson SJ, Tauer K, Yang SC, Gregory K, Hughes $\mathrm{M}$ and National Comprehensive Cancer Network: Nonsmall cell lung cancer, version 6. 2015. J Natl Compr Canc Netw 13: 515-524, 2015.

18 Novello S, Barlesi F, Califano R, Cufer T, Ekman S, Levra MG, Kerr K, Popast S, Reck M, Senan S, Simo GV, Vansteenkiste J and Peters S: Metastatic non-small-cell lung cancer: ESMO Clinical Practice Guidelines for diagnosis, treatment and followup. Ann Oncol 27: 1-27, 2016.

19 Kim J, Cho CK and Yoo HS: Survival analysis of advanced nonsmall cell lung cancer patients treated by using wheel balance cancer therapy. Integr Cancer Ther 15: 467-477, 2016. 